\title{
The effect of sous vide packaging with rosemary essential oil on storage quality of fresh-cut potato
}

\author{
Valeria Rizzo, Luana Amoroso, Fabio Licciardello, Agata Mazzaglia, Giuseppe Muratore, \\ Cristina Restuccia*, Sara Lombardo, Gaetano Pandino, Maria Gabriella Strano, \\ Giovanni Mauromicale
}

Di3A - Dipartimento di Agricoltura, Alimentazione e Ambiente, University of Catania, Via Santa Sofia, 100, 95123, Catania, Italy

\section{A R T I C L E I N F O}

\section{Keywords:}

Potato cultivar

Sous vide

Rosemary essential oil

Quality

\begin{abstract}
A B S T R A C T
Selection of suitable raw materials and technologies are essential for the fresh-cut segment, since they represent key factors to be competitive in the modern markets. This study aimed at assessing the suitability of six early potato cultivars, grown in an experimental field, for minimal processing. In particular, the sous vide packaging method, in association with rosemary essential oil (REO), was evaluated as a strategy for the quality preservation of sliced potatoes. Physical, mechanical, chemical, microbiological and sensory characteristics were monitored in order to estimate qualitative changes of the product over refrigerated storage. Results demonstrated that the synergic use of REO and sous vide packaging had a positive effect on texture, and limited the growth of mesophilic bacteria and Enterobacteriaceae over the storage period; it also ensured a certain retention of ascorbic acid, total polyphenol content, and antioxidant activity. Hence, the proposed technological strategy could represent a valid solution for the preservation of sliced potatoes, contributing to limit, for the most suitable cultivars identified as Fontane and Marabel, the quality decrease until 11 days of cold storage.
\end{abstract}

\section{Introduction}

Fresh-cut products represent a good chance for the food industry to increase market sales with a type of product able to fully respond to the demand for healthy and convenient foods by modern consumers. The fresh-cut industry has expanded to a wide variety of packaged fresh-cut fruits and vegetables; among them, fresh-cut potatoes are increasingly preferred by consumers for their high added value and ease of use, both at home and in the food service industry.

Therefore, processing as fresh-cut products may provide further market margins for Italian potatoes that are mainly cropped in an "early" cycle (planting from November to January and harvesting from March to early-June) (Mauromicale, Signorelli, Ierna, \& Foti, 2003) and are appreciated for their high content of ascorbic acid, potassium, phosphorus and calcium (Lombardo, Lo Monaco, Pandino, Parisi, \& Mauromicale, 2013a; Lombardo, Pandino, \& Mauromicale, 2013b, 2014), polyphenols and carotenoids (Buono et al., 2009). In this view, extrapolation to the early crop from knowledge on the behavior of the main crop is not straightforward, since the former tubers, being immature, differ qualitatively from those of the main crop.

Packaging technologies allow to implement strategies for quality preservation. The high quality of the starting product and the efficiency of the conditioning steps could be drastically affected by the use of unsuitable plastic films, which could cause an imbalance of the product metabolism and accelerate deterioration.

The sous vide is a combined technique used for raw or partially cooked (grilled or baked) foods, packaged in modified atmospheres, hermetically sealed and, if applicable, pasteurized to preserve the nutritional and sensory traits (FDA, 2013, p. 768). The benefits of sous vide are validated by several studies (Baldwin, 2012; Fabbri \& Crosby, 2016; Tudela, Cantos, Espiän, Tomaäs-Barberaän, \& Gil, 2002).

Further directions of scientific research concern the use of natural antimicrobials in fruit and vegetable packaging. To respond to many consumers' requests to reduce or eliminate the synthetic preservatives, plant derived compounds, such as essential oils (EOs), are frequently used, often through dipping techniques or, more recently, by including them within plastic materials. Rosemary (Rosmarinus officinalis L.) essential oil (REO) has been shown pronounced antibacterial and antifungal activity and the major constituents were 1,8-cineole, $\alpha$-pinene, borneol, verbenone and camphor (Jiang et al., 2011). In addition, the possible combination of REO with aroma notes of processed vegetables has been suggested by Ayala-Zavala, Gonzales-Aguilar, and Del-Toro-

\footnotetext{
* Corresponding author.

E-mail address: crestu@unict.it (C. Restuccia).
} 
Sanchez (2009) for fresh-cut potatoes.

The aim of this work was to evaluate the suitability to minimal processing of six different early potato cultivars, and the effectiveness of vacuum packaging associated with the rosemary essential oil (REO) treatment, as a strategy for the preservation of sliced potatoes, destined to be cooked with the sous vide technique. The effectiveness of the adopted procedures was evaluated by monitoring physical, mechanical, chemical, microbiological and sensory quality parameters during cold storage.

\section{Materials and methods}

\subsection{Field growing conditions and plant material}

Field-experiments were conducted during the 2015 growing season at a commercial farm located in the Plain of south Siracusa $\left(36^{\circ} 55^{\prime} \mathrm{N}\right.$, $15^{\circ} 20^{\prime} \mathrm{E}, 20 \mathrm{~m}$ a.s.l.), a typical area for "early" crop potato cultivation in southern Italy. The local climate features are characterized by a mild winter and a hot, dry summer; detailed meteorological data pertaining to the period January to June 2015 were reported by Lombardo, Pandino, and Mauromicale (2017). Based on USDA Soil Taxonomy classification the soil type is Calcixerollic Xerofluven; the soil texture was loamy.

The processing was carried out on potato tubers of six different cultivars: Arinda, Elodie, Erika, Fontane, Marabel and Ranomi. Details of the provenance and EAPR cooking type of the tested cultivars are reported by Lombardo et al. (2017). All of them present yellow skin and pulp. Disease-free, non pre-sprouted seed tubers were manually planted in January at a rate of 4.5 plants $\mathrm{m}^{-2}$, and arranged in a randomized block design with three replications. The cultivation system followed local commercially used procedures, as already detailed by Lombardo et al. (2017). Drip irrigation was provided once the accumulated daily evaporation rate (derived from measurements of an unscreened class APan evaporimeter) had reached $30 \mathrm{~mm}$. On the whole, $120 \mathrm{~mm}$ water was applied over the whole growing period through five applications. Tubers were harvested $\sim 120$ days after planting (when $70 \%$ of the haulms were dry), and a representative sample of marketable tubers per cultivar and replicate (average tuber weight: $150 \pm 30 \mathrm{~g}$ ) was directly transported to the Di3A laboratories.

\subsection{Packaging material}

Sous vide cooking bags, $20 \times 30 \mathrm{~cm}$, by ORVED S.p.A. (Musile di Piave, VE, Italy) were used. Bags were made using a bi-layer film made of: bi-oriented polyamide (OPA, $15 \mu \mathrm{m}$ thick, $17.2 \mathrm{~g} \mathrm{~m}^{-2}$ ) for the side not in contact with the product; two-component polyurethane $\left(3 \mathrm{~g} \mathrm{~m}^{-2}\right)$ as adhesive; cast polypropylene (CPP, $60 \mu \mathrm{m}$ thick, $54 \mathrm{~g} \mathrm{~m}^{-2}$ ) for the side in contact with the product. These OPA/CPP bags are designed for vacuum storage and sous vide cooking up to $121^{\circ} \mathrm{C}$ for $30 \mathrm{~min}$.

\subsection{Sample preparation}

On the basis of preliminary internal tests, as well as studies carried out by Ayala-Zavala et al. (2009), REO was considered the most appropriate and kindred with the preparation of fresh-cut potatoes.

All varieties were washed with tap water to remove soil residues, and immersed for 2 min into a $2 \% \mathrm{NaClO}$ solution $(0.011 \%$ active chlorine). Potatoes were then peeled and cut, using a manual slicer, into $1 \mathrm{~cm}$-thick slices; a further immersion ( $2 \mathrm{~min}$ ) into distilled water was done to remove part of the starch. Slices were manually centrifuged to remove excess water, and weighed: about $10 \mathrm{~kg}$ sliced potatoes were used for each thesis; half was uniformly treated with a mixture of $150 \mathrm{~mL}$ peanut seed oil added with $0.5 \%(\mathrm{v} / \mathrm{v}) \mathrm{REO}$, while the other half was dipped into peanut oil and used as control. Each bag contained about 200 g potatoes ( $\sim 6-8$ slices). The bags were finally vacuum- sealed employing a vacuum packaging machine (DELTA 30, FIMA srl, Ariano Irpino, AV, Italy). The whole process was carried out at room temperature under suitable hygienic conditions. All samples were stored under refrigerated conditions at $+4 \pm 2{ }^{\circ} \mathrm{C}$ until analyses.

\subsection{Sampling}

For each variety under study, 24 bags were prepared, for a total of 288 samples (24 bags $\times 6$ varieties $\times 2$ dipping treatments). The determination of quality parameters was performed, for each variety and dipping treatment, at the day of packaging, and after 4, 7 and 11 days of storage, analyzing, at each sampling time two bags for each batch.

\subsection{Color and texture determination}

Surface color of potato slices was measured according to CIE $\mathrm{L}^{*} \mathrm{a} * \mathrm{~b}$ * scale as reported in Rizzo and Muratore (2009), using a portable colorimeter (NR-3000, Nippon Denshoku Ind. Co., Ltd., Japan). The instrument was previously calibrated with a standard white tile (UE certificated) with the following parameters: $\mathrm{X}=80.70, \mathrm{Y}=84.42$, $\mathrm{Z}=86.39$ with illuminant $\mathrm{D} 65 / 10^{\circ}$ (spectral distribution of light energy in the areas of Northern Europe). Values reported as L $=$ lightness, $\mathrm{a}=$ redness and $\mathrm{b}=$ yellowness are an average of 6 measurements (Chen, Zhu, Zhang, Niu, \& Du, 2010).

The texture properties were evaluated measuring the maximum shear force using a ZwickRoell z 0.5 Texture Analyzer (Zwick GmbH \& Co., Ulm, Germany) provided with a $500 \mathrm{~N}$ nominal force load cell and a stainless steel probe (length $5 \mathrm{~mm}$ ). Cutting tests were carried out at the following conditions: preload $0.2 \mathrm{~N}$, test speed $20 \mathrm{~mm} / \mathrm{min}$. Firmness was expressed as the maximum force $(\mathrm{N})$ : data were recorded as the average of 6 measurements and were elaborated by the Testxpert II v. 2.2 software (Zwick GmbH \& Co., Ulm, Germany).

\subsection{Microbiological analyses}

Potato samples $(10 \mathrm{~g})$ were aseptically transferred into Stomacher bags, added with $90 \mathrm{~mL}$ of sterile physiologic solution $\left(9 \mathrm{gL}^{-1} \mathrm{NaCl}\right)$ and homogenized for $3 \mathrm{~min}$ in a stomacher (Lab-Blender 400, Brinkmann, Westbury, NY, USA). The total mesophilic bacteria (TMB) were counted on Plate Count Agar (Oxoid, Basingstoke, UK) with cycloheximide $0.1 \%$ solution (Oxoid), incubated at $32{ }^{\circ} \mathrm{C}$ for $48 \mathrm{~h}$; the yeast and mould (YM) counts were performed on Sabouraud Dextrose Agar (Oxoid) with $0.1 \mathrm{~g} \mathrm{~L}^{-1}$ chloramphenicol (Oxoid) incubated at $25^{\circ} \mathrm{C}$ for $48-72 \mathrm{~h}$; the Enterobacteriaceae (TEB) were determined on Violet Red Bile Glucose Agar (Oxoid) incubated at $32^{\circ} \mathrm{C}$ for $24-48 \mathrm{~h}$. All microbiological counts were performed in triplicate and expressed as average $\log _{10} \mathrm{cfu}^{-1}$ sample.

\subsection{Chemical analyses}

The ascorbic acid content (AsAC) was determined by a high performance liquid chromatography method (HPLC), as previously described by Lombardo et al. (2013b) and expressed as $\mathrm{mg} \mathrm{kg}^{-1}$ of dry matter (DM). Briefly, $5 \mathrm{~g}$ of lyophilized sample were mechanically stirred in $15 \mathrm{~mL}$ of a $4.5 \%(\mathrm{w} / \mathrm{v})$ solution of metaphosphoric acid for $15 \mathrm{~min}$. The mixture was filtered and diluted with HPLC grade water; an aliquot was filtered through a $0.45 \mathrm{~mm}$ Millipore filter prior to injection into the chromatographic column. Ascorbic acid was identified by its retention time and UV spectral data at $245 \mathrm{~nm}$ as compared to commercially available standard.

Total polyphenols were extracted according to Lombardo et al. (2013b) and quantified using the Folin-Ciocalteu assay (Singleton \& Rossi, 1965). The total polyphenol content (TPC) was determined on the basis of a standard calibration curve generated with known amounts of chlorogenic acid as reported in Licciardello et al. (2018) and data were expressed as $\mathrm{g}$ of chlorogenic acid equivalent (CAE) $\mathrm{kg}^{-1}$ of DM. 
Table 1

Percentage of total mean square of the studied main effects and their interactions resulting from analysis of variance.

\begin{tabular}{|c|c|c|c|c|c|c|c|c|c|c|c|}
\hline \multirow[t]{2}{*}{ Source of variation } & \multirow[t]{2}{*}{ Degree of freedom } & \multicolumn{10}{|c|}{ Qualitative trait } \\
\hline & & TPC & AsAC & AA & Text & $\mathrm{L}$ & $\mathrm{a}$ & $\mathrm{b}$ & TMB & TEB & YM \\
\hline Cultivar (C) & 5 & $21.8^{* * * *}$ & $4.0^{* *}$ & $4.7^{*}$ & $41.2^{* * *}$ & $1.3^{\mathrm{NS}}$ & $3.5^{\mathrm{NS}}$ & $1.6^{\mathrm{NS}}$ & $2.5^{* * *}$ & $3.4^{* * * *}$ & $4.6^{* * *}$ \\
\hline Dipping treatment (D) & 1 & $8.3^{* * *}$ & $4.3^{* *}$ & $22.5^{* * *}$ & $27.5^{* * *}$ & $0.5^{\mathrm{NS}}$ & $1.2^{\mathrm{NS}}$ & $4.6^{\mathrm{NS}}$ & $3.3^{* * *}$ & $33.3^{* * *}$ & $1.1^{* * * *}$ \\
\hline Storage time (S) & 3 & $63.8^{* * *}$ & $88.2^{* * *}$ & $65.1^{* * *}$ & $22.5^{* * *}$ & $32.7^{* * *}$ & $78.1^{* * *}$ & $77.8^{* * *}$ & $92.2^{* * *}$ & $53.2^{* * *}$ & $89.2^{* * * *}$ \\
\hline (C) $x(D)$ & 5 & $0.3^{\mathrm{NS}}$ & $0.1^{\mathrm{NS}}$ & $1.3^{\mathrm{NS}}$ & $4.1^{* *}$ & $2.2^{\mathrm{NS}}$ & $2.3^{\mathrm{NS}}$ & $4.6^{\mathrm{NS}}$ & $0.8^{* * *}$ & $7.7^{* * *}$ & $2.5^{* * *}$ \\
\hline (C) $\times(S)$ & 15 & $3.2^{*}$ & $3.0^{*}$ & $3.9^{*}$ & $2.7^{* *}$ & $0.7^{\mathrm{NS}}$ & $5.5^{*}$ & $2.2^{\mathrm{NS}}$ & $0.4^{* * *}$ & $0.8^{* * * *}$ & $1.2^{* * *}$ \\
\hline (D) $x(S)$ & 3 & $1.8^{\mathrm{NS}}$ & $0.1^{\mathrm{NS}}$ & $0.1^{\mathrm{NS}}$ & $0.1^{\mathrm{NS}}$ & $1.9^{\mathrm{NS}}$ & $7.6^{* *}$ & $4.4^{\mathrm{NS}}$ & $0.6^{* * *}$ & $0.9^{* * *}$ & $0.7^{* * *}$ \\
\hline (C) $x(D) \times(S)$ & 15 & $0.8^{\mathrm{NS}}$ & $0.3^{\mathrm{NS}}$ & $2.4^{\mathrm{NS}}$ & $1.9^{\mathrm{NS}}$ & $0.4^{\mathrm{NS}}$ & $1.8^{\mathrm{NS}}$ & $4.8^{\mathrm{NS}}$ & $0.2^{* * *}$ & $0.7^{* * *}$ & $0.7^{* * *}$ \\
\hline Total mean square & & 24.2 & 249740 & 4715 & 23050 & 101.8 & 407.1 & 253.0 & 85.4 & 25.2 & 46.2 \\
\hline
\end{tabular}

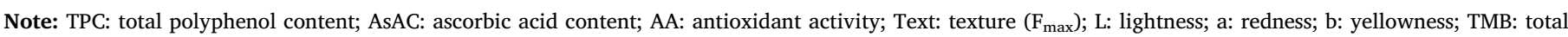

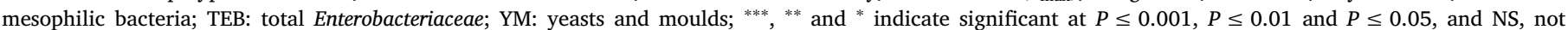
significant.

The antioxidant activity (AA) was evaluated on the same extracts submitted to TPC determination, as percentage inhibition of DPPH radical (Brand-Williams, Cuvelier, \& Berset, 1995; Licciardello et al., 2018). An aliquot $(0.1 \mathrm{~mL})$ of each extract was added to $3.9 \mathrm{~mL}$ of freshly prepared methanolic solution containing $0.24 \mathrm{~g} \mathrm{~L}^{-1} \mathrm{DPPH}$, and held in the dark for $30 \mathrm{~min}$ at room temperature. The absorbance was then measured at $515 \mathrm{~nm}$, using a Shimadzu $1601 \mathrm{UV}$-Visible spectrophotometer (Shimadzu Corp., Tokyo, Japan). The percentage inhibition of DPPH was obtained by the following equation: [(AC(0) - AS $(\mathrm{t})) / \mathrm{AC}(0)] \times 100$, where $\mathrm{AC}(0)$ is the absorbance of the blank control at the beginning of the assay, and AS(t) the sample absorbance after $30 \mathrm{~min}$.

All chemical analyses were performed in triplicate. All reagents and solvents were purchased from Sigma-Aldrich (Milan, Italy) and were of analytical or HPLC grade. Bi-distilled water was used throughout the analytical trials.

\subsection{Sensory evaluation of cooked potatoes}

Sensory analysis was performed at the packaging time and after 4, 7 and 11 days of refrigerated storage, on the samples after boiling the sous vide bags for $15 \mathrm{~min}$. The assay was intended to detect the possible influence of the REO on the sensory attributes of cooked potatoes, but also to select the cultivars with the best performances after cooking. Following the UNI 10957 (2003), the profile of potato samples was defined using a panel of ten trained judges (ISO 8586, 2012), who identified 19 attributes: 1 for appearance (browning), 1 for rheology (firmness), 5 for odour (potato, rosemary, soil, herbaceous and offodour), 4 for taste (salt, sweet, sour and bitter), 2 for touch in mouth (chewable and adhesive), 5 for flavour (potato, rosemary, soil, herbaceous and off-flavour). The panel evaluated the samples using a discontinuous scale from 1 (absence of sensation) to 9 (extremely intense).

\subsection{Statistical analysis}

Bartlett's test was used to test the homoscedasticity, following which the data were subjected to a three-way analysis of variance (ANOVA) as a factorial combination of "cultivar (6) $\times$ dipping treatment (2) $\times$ storage time (4)". Means were separated by a least significance difference (LSD) test, when the $F$-test was significant and with a significance level of $P \leq 0.05$. Percent values were transformed to arcsin $\sqrt{\mathrm{X}}$ (Bliss transformation) prior to analysis and then subjected to ANOVA; untransformed data were reported and discussed. Furthermore, correlation analysis was performed to evaluate the relationship between ascorbic acid and total polyphenol content and antioxidant activity of samples.

The sensory data for each attribute were submitted to one-way ANOVA using samples as factors. The significance was tested by means of the $F$-test. To differentiate the samples, the mean values were submitted to the multiple comparison test using the least significant difference (LSD) procedure.

\section{Results and discussion}

\subsection{Color analysis}

As reported in Table 1, color parameters were affected by storage time; in particular, $L$ increased from 91.6 to 95.2 (Table 2). Storage time explained $32.7 \%$ variance for $L, 78.1 \%$ for $a$ and $77.8 \%$ for $b . L$ and $b$ were not altered by cultivar, dipping treatment and their interaction (Table 1$)$, meanwhile $a$ showed a $5.5 \%$ effect $(P \leq 0.05)$ for the cultivar $\times$ storage interaction and a $7.6 \%$ effect for dipping treatment $\times$ storage $(P \leq 0.01)$. Also considering the different cultivars, $L$ was the parameter that gave back some small differences; in particular cv. Arinda had the highest value (94.0), Elodie, Erika and Ranomi were similar (93.5, on average), as well as similar were Fontane and Marabel (Table 2). All cultivars showed comparable $b$ values, while two sample classes could be observed regarding the red-green parameter; in particular, Elodie and Fontane had significantly lower values than the other ones. No particular difference could be attributed to the dipping treatment, suggesting that color is not influenced by the addition of REO. Among color parameters, $L$ that was considered by Cantos, Tudela, Gil, and Espín (2002) as the best indicator of browning appearance in fresh-cut potato strips, was detected with slight differences among cultivars only in sliced potatoes without EO. Referring to the cultivars under study, the order of browning susceptibility was: Arinda $>$ Elodie $=$ Erika $=$ Ranomi $>$ Fontane $=$ Marabel.

\subsection{Texture tests}

The analysis of variance (Table 1 ) showed that cultivar, dipping treatment and storage time had a significant $(P<0.01)$ effect on the shear force values. 'Cultivar $\times$ storage' and 'cultivar $\times$ dipping treatment' interactions significantly ( $P \leq 0.01)$ affected texture (Figs. 1 and $2)$. In detail, cv. Fontane showed the highest shear force $(134.9 \mathrm{~N})$, followed by Elodie and Marabel, while Arinda, Ranomi and Erika (84.3 $\mathrm{N}$, on average) had the lowest values, suggesting that within the cultivars there were significant $(P<0.05)$ differences, as well as the dipping in peanut oil and REO (Table 2). Texture of sliced potatoes with REO was kept higher in all cultivars probably due to an effect of EO in the reduction of the softening rate (Ayala-Zavala et al., 2009). 
Also storage affected texture, that varied from $110.4 \mathrm{~N}$ just after cutting, to $82.6 \mathrm{~N}$ at the end of storage, confirming that the texture of sliced potatoes is determined by several mutually dependent factors, from genetically determined characteristics of the fresh product to agronomic, processing and storage conditions (García-Segovia, AndrésBello, \& Martínez-Monzo, 2008).

\subsection{Microbiological analyses}

All the considered experimental factors affected the microbiological quality of sliced potatoes, showing high levels of percentage of total variation for the three monitored microbial groups (Table 1).

Significant differences $(P \leq 0.05)$ were found for each microbiological parameter among potato cultivars. TMB ranged from 5.59 (cv. Erika) to $4.80 \log \mathrm{cfu}^{-1}$ (cv. Fontane); TEB count had the highest value in Elodie (3.63 log cfu $\mathrm{g}^{-1}$ ) and the lowest in Erika (2.84 log cfu $\mathrm{g}^{-1}$ ); wider differences among cultivars were recorded for YM counts, which ranged from a maximum of $4.50 \mathrm{log} \mathrm{cfu}^{-1}$ (cv. Marabel) to a minimum of $2.26 \mathrm{log} \mathrm{cfu} \mathrm{g}^{-1}$ (cv. Arinda) (Table 2). The wide variability in microbial population level found within potato varieties has been observed by İnceoğlu, Salles, van Overbeek, and van Elsas (2010), who demonstrated that the bacterial community structures are affected by physiological cultivar differences.

With reference to treatment with REO, average TMB and TEB counts of sliced potatoes added with EO were significantly reduced $(P \leq 0.05)$; a different trend was instead observed for fungal count (Table 2).

Referring to storage time, all the considered microbial groups underwent a gradual increase until the end of storage (Table 2). At the end of storage, TMB was well below the recommended limit of $8 \log \mathrm{cfu} \mathrm{g}^{-1}$ proposed by CNERNA-CNRS (1996), since at the last day of storage the average plate count was $6.94 \log \mathrm{cfu}^{-1}$; on the contrary, the average YM counts marginally exceeded (5.06 $\log \mathrm{cfu}^{-1}$ ) the relative recommended limit of 5 log cfu $\mathrm{g}^{-1}$ (CNERNA-CNRS, 1996), but without the occurring of sensory defects as previously demonstrated on readyto-fry potato sticks (Licciardello et al., 2018) and on different minimally processed vegetables (Licciardello et al., 2017; Muratore et al., 2015; Scuderi et al., 2011) (Table 2).

As it can be inferred from Table 1, the analysis of variance revealed a significant $(P \leq 0.001)$ influence of all the considered interactions for all of the considered microbial groups.

The addition of REO significantly $(P \leq 0.05)$ controlled the growth of TMB and TEB when compared to the relative control samples, although with different efficacy among varieties (Fig. 3). In detail, the EO treatment reduced, at the end of storage, TMB counts from about 0.20 $\log \mathrm{cfu}^{-1}$ (cv. Erika) to more than $0.70 \log \mathrm{cfu}^{-1}$ (cv. Marabel); in the case of cv. Elodie, the EO addition did not produce any significant variation in TMB levels. TEB counts were significantly reduced at the end of storage for all cultivars. The differences in efficacy levels of REO among cultivars can be attributed to the differences in bacterial communities and to the different chemotype of plant EOs (Ojeda-Sana, van Baren, Elechosa, Juárez, \& Moreno, 2013). Conversely, the YM population was not affected by EO, except in Elodie where a reduction of $1.12 \log \mathrm{cfu} \mathrm{g}^{-1}$ was reached at the 11 th day of storage.

\subsection{Antioxidant compounds content and their activity}

The effect of cultivar, storage time, dipping treatment and their interactions on the AsAC, TPC and AA in the processed samples are presented in Table 1 . Most of the variance in these parameters was explained by storage time (88.2-63.8 and $65.1 \%$, respectively), while cultivar and dipping treatment significantly contributed only to the variance in TPC and AA (accounting for 21.8 and $22.5 \%$, respectively). On average, a further $3.4 \%$ was associated with the two-way interaction between cultivar and storage time (Table 1).

As shown in Table 2, AsAC, TPC and AA declined throughout the storage time. At least for AsAC, this trend was previously observed in 


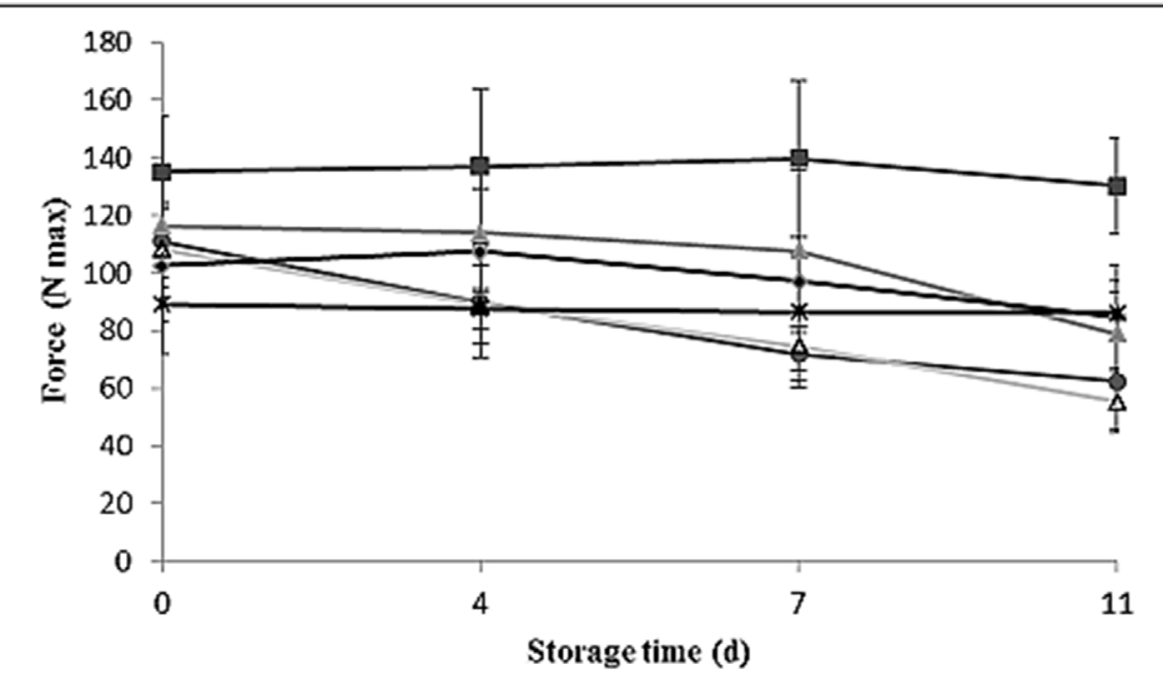

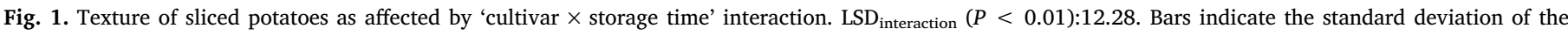
mean. $-\bullet$ Arinda $\rightarrow-$ Elodie $\Delta-$ Erika $\rightarrow-$ Fontane -+- Marabel $\rightarrow$ Ranomi
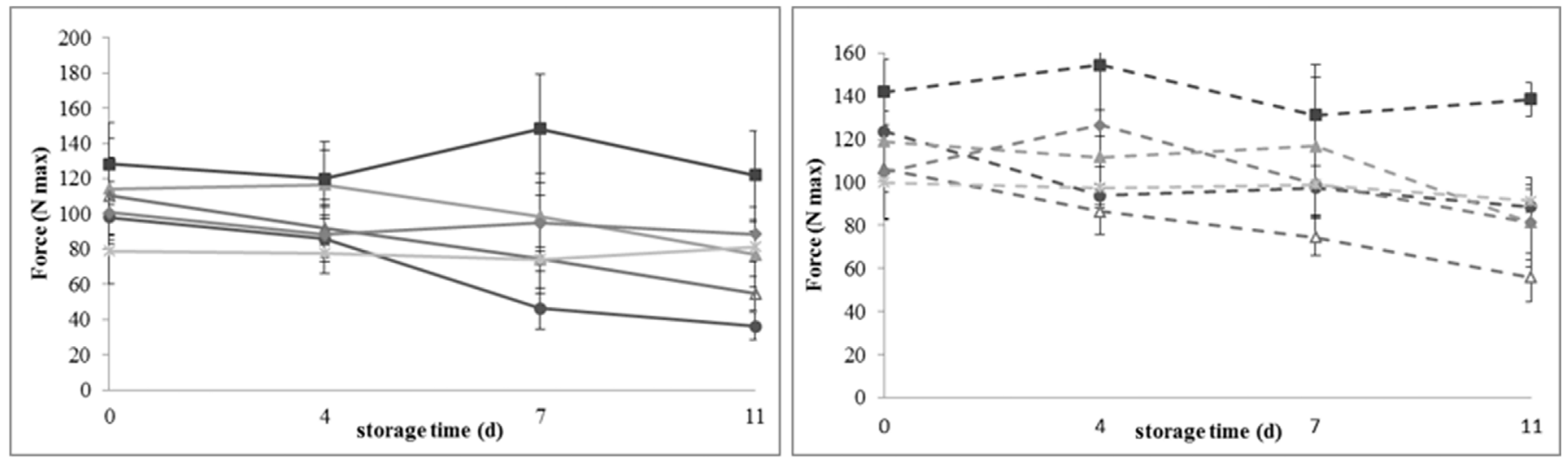

EO: essential oil

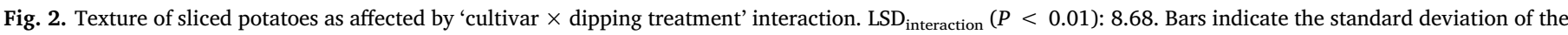
mean.-

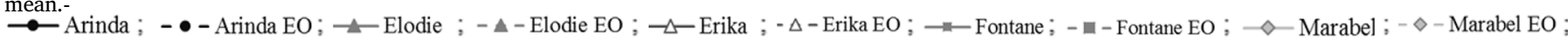

-*-Ranomi ; - * - Ranomi EO
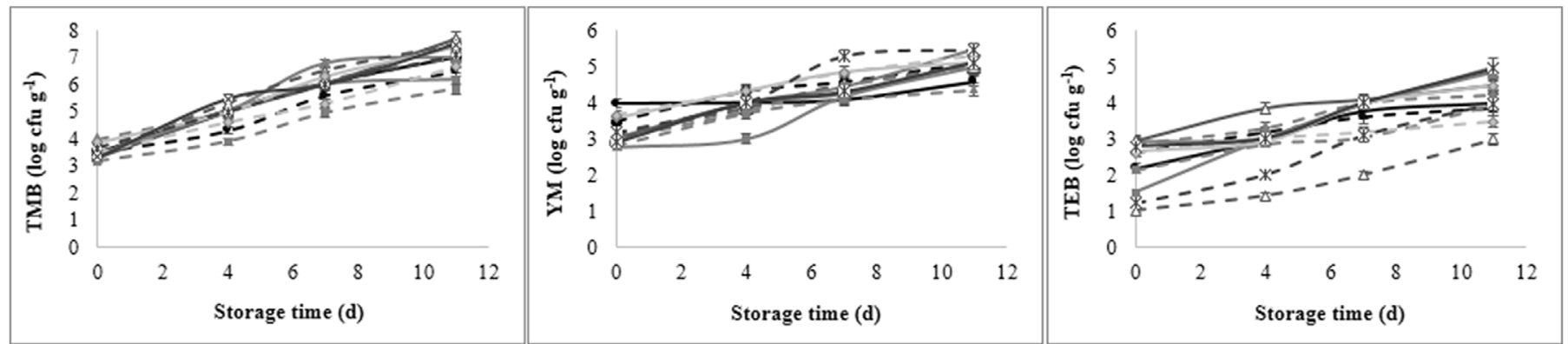

TMB (Total Mesophilic Bacteria); YM (Yeasts and Moulds); TEB (Total Enterobacteriaceae). EO: essential oil.

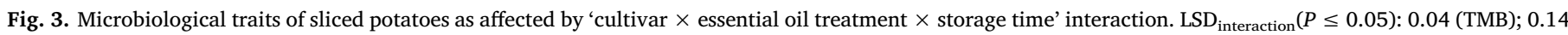
(YM); 0.03 (TEB). Bars indicate the standard deviation of the mean.

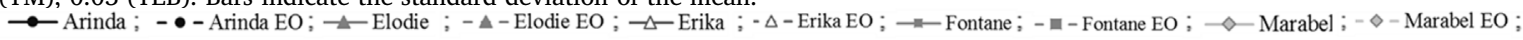

$-*-$ Ranomi ; $-*-$ Ranomi EO 


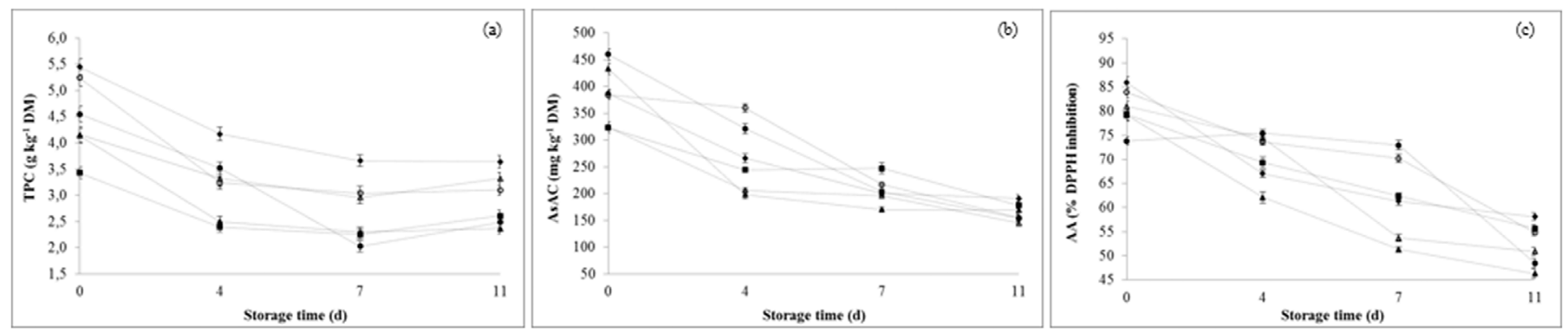

TPC (total polyphenol content); AsAC (ascorbic acid content); AA (antioxidant activity); CAE (chlorogenic acid equivalent).

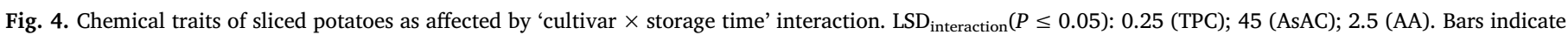

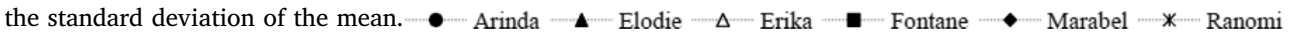

main potato crop (Dale, Griffiths, \& Todd, 2003) and in other vegetables, such as globe artichoke (Lombardo et al., 2015); while our data on TPC disagree with previous literature on fresh-cut potatoes (Cantos et al., 2002; Tudela et al., 2002). A possible explanation for the reduction of TPC in our samples was attributable to their dipping in peanut oil. Indeed, in complex foods (with both an aqueous and a lipid phase) both redox reactions and lipid oxidation products have unpredictable consequences on the antioxidant properties and stability in foods. In this light, changes in the initial level (at the day of processing) of AsAC, TPC and AA, as compared to the data reported by Lombardo et al. (2017) for the unprocessed tubers, are attributable to the undesirable enzymatic reactions (mediated by PAL, PPO and POD) that immediately occur in minimally processed vegetables (Nicoli, Anese, \& Parpinel, 1999). In particular, from the processing day to the 11th day of cold storage, the AsAC underwent a stronger reduction ( $\sim 77 \%)$ than observed for TPC and AA (accounting for both $\sim 35 \%$ ). This should be attributed to the primary role of AsAC in maintaining the product enduse quality, thanks to its well-known reducing activity (Cornacchia, Cabezas-Serrano, Amodio, \& Colelli, 2011). Indeed, considering all the data obtained for the chemical parameters under study, the AA was more correlated with AsAC $\left(r=0.71^{* * *}\right)$ than with TPC $\left(r=0.65^{* * *}\right)$, as also reported by Cabezas-Serrano, Amodio, Cornacchia, Rinaldi, and Colelli (2009). However, the early potato cultivars tested in our experiment showed a different behaviour in terms of reduction of antioxidant compounds and activity during cold storage (Fig. 4). For both TPC and AsAC there was a major decrease during the storage time for Arinda, Elodie and Ranomi cultivars (Fig. 4 a-b), which also harboured a greater AA reduction than the others under study (Fig. 4c).

Among cultivars, Marabel had a significantly $(P \leq 0.05)$ higher TPC than the other cultivars examined, while showing one of the lowest AsAC reduction after 11th day of cold storage (Fig. 4 a-b). Indeed, a high level of antioxidant substances in the samples may be considered a natural tool to maintain the quality of fresh-cut product. Also in a study conducted by Cabezas-Serrano et al. (2009), Marabel revealed the best potential in terms of storability after processing than other cultivars.

As shown in Table 2, the treatment B ensured a certain retention of AsAC, TPC and AA. Indeed, the addition of REO may have provided further antioxidants and, hence, minimised the reduction-oxidation reaction rate of these substances under refrigerated conditions. The ability of EOs to preserve the antioxidant characteristics of foods, when applied in active packaging and edible coatings, has been already demonstrated on table grapes (Valero et al., 2006), strawberries (Wang, Wang, Yin, Parry, \& Yu, 2007) and bayberries (Jin et al., 2012). Particularly, the REO consists of monoterpenic hydrocarbons, oxygenated monoterpenes and sesquiterpene hydrocarbons, which have both antioxidant and antimicrobial activities (Moreno, Scheyer, Romano, \& Vojnov, 2006; Özcan \& Chalchat, 2008). Therefore, our results highlighted as the dipping with REO is crucial to maintain a high antioxidant potential also in the sliced potato products.

\subsection{Sensory evaluation}

Tables 3 and 4 report the sensory attributes which significantly differentiated, over the storage time, the samples dipped in peanut oil (A) and in peanut oil with REO (B). The intensity (mean score) was reported only for the significantly different attributes $(P \leq 0.05)$.

At packaging time, samples A were significantly different for the attributes browning, soil odor and sweet. The cv. Fontane showed the highest intensity for browning and sweet, while Erika and Ranomi harboured the highest intensity for soil odor. After 4 days of cold storage, there were no significant differences among samples. After 7 days, samples significantly differed in terms of browning, firmness, floury and adhesive. In particular, Ranomi and Fontane cultivars reported the highest intensity of browning, while Elodie and Arinda had the lowest values of firmness and the highest levels of floury than the other

Table 3

Mean scores of the significant sensory attributes of sliced potatoes dipped in peanut oil (A).

\begin{tabular}{llllllll}
\hline $\begin{array}{l}\text { Storage time } \\
\text { (d) }\end{array}$ & Attribute & Arinda & Elodie & Erika & Fontane & Marabel & Ranomi \\
\hline 0 & & & & & & & \\
\hline & Browning & $5.3^{\mathrm{a}}$ & $5.2^{\mathrm{a}}$ & $4.8^{\mathrm{a}}$ & $7.1^{\mathrm{b}}$ & $4.5^{\mathrm{a}, *}$ & $5.8^{\mathrm{ab}}$ \\
& Soil odor & $2.3^{\mathrm{a}}$ & $3.9^{\mathrm{ab}}$ & $5.3^{\mathrm{b}}$ & $2.2^{\mathrm{a}}$ & $3.9^{\mathrm{ab}}$ & $4.2^{\mathrm{b}}$ \\
4 & Sweet & $3.9^{\mathrm{bc}}$ & $1.9^{\mathrm{a}}$ & $3.2^{\mathrm{abc}}$ & $4.6^{\mathrm{c}}$ & $2.6^{\mathrm{ab}}$ & $3.5^{\mathrm{bc}}$ \\
7 & No significant difference & & & & \\
& Browning & $4.3^{\mathrm{a}}$ & $4.9^{\mathrm{ab}}$ & $5.7^{\mathrm{abc}}$ & $7.1^{\mathrm{c}}$ & $6.4^{\mathrm{bc}}$ & $6.8^{\mathrm{c}}$ \\
& Firmness & $4.7^{\mathrm{a}}$ & $5.0^{\mathrm{a}}$ & $6.6^{\mathrm{b}}$ & $6.9^{\mathrm{b}}$ & $7.3^{\mathrm{b}}$ & $6.6^{\mathrm{b}}$ \\
& Floury & $6.8^{\mathrm{c}}$ & $6.5^{\mathrm{c}}$ & $4.7^{\mathrm{ab}}$ & $5.9^{\mathrm{bc}}$ & $4.6^{\mathrm{ab}}$ & $3.9^{\mathrm{a}}$ \\
& Adhesive & $5.6^{\mathrm{c}}$ & $5.1^{\mathrm{bc}}$ & $3.9^{\mathrm{ab}}$ & $5.5^{\mathrm{c}}$ & $3.4^{\mathrm{a}}$ & $3.9^{\mathrm{ab}}$ \\
& Firmness & $5.5^{\mathrm{ab}}$ & $4.4^{\mathrm{a}}$ & $6.2^{\mathrm{bc}}$ & $7.4^{\mathrm{c}}$ & $6.6^{\mathrm{bc}}$ & $6.6^{\mathrm{bc}}$ \\
& Off-odor & $2.2^{\mathrm{a}}$ & $1.7^{\mathrm{a}}$ & $4.1^{\mathrm{b}}$ & $1.8^{\mathrm{a}}$ & $1.5^{\mathrm{a}}$ & $1.5^{\mathrm{a}}$ \\
& Floury & $6.4^{\mathrm{c}}$ & $6.1^{\mathrm{bc}}$ & $5.6^{\mathrm{bc}}$ & $4.5^{\mathrm{ab}}$ & $4.5^{\mathrm{ab}}$ & $3.6^{\mathrm{a}}$ \\
& Off-flavor & $2.2^{\mathrm{a}}$ & $2.2^{\mathrm{a}}$ & $3.9^{\mathrm{b}}$ & $2.7^{\mathrm{ab}}$ & $1.3^{\mathrm{a}}$ & $1.9^{\mathrm{a}}$ \\
& & & & & & &
\end{tabular}

* Values marked with different letters in the same row are significantly different $(P \leq 0.05)$ according to the LSD multiple comparison test.

Table 4

Mean scores of the significant sensory attributes of sliced potatoes dipped in peanut oil and rosemary essential oil (B).

\begin{tabular}{llllllll}
\hline $\begin{array}{l}\text { Storage time } \\
\text { (d) }\end{array}$ & Attribute & Arinda & Elodie & Erika & Fontane & Marabel & Ranomi \\
\hline 0 & \multicolumn{7}{l}{ No significant difference } \\
4 & Floury & $5.6^{\mathrm{bc}}$ & $4.4^{\mathrm{ab}}$ & $4.1^{\mathrm{ab}}$ & $6.6^{\mathrm{c}}$ & $4.0^{\mathrm{ab} *}$ & $3.6^{\mathrm{a}}$ \\
7 & Firmness & $6.7^{\mathrm{b}}$ & $4.7^{\mathrm{a}}$ & $6.6^{\mathrm{b}}$ & $4.5^{\mathrm{a}}$ & $6.6^{\mathrm{b}}$ & $6.5^{\mathrm{b}}$ \\
& Floury & $5.0^{\mathrm{ab}}$ & $6.8^{\mathrm{bc}}$ & $6.0^{\mathrm{abc}}$ & $7.4^{\mathrm{c}}$ & $4.8^{\mathrm{a}}$ & $5.3^{\mathrm{ab}}$ \\
11 & Floury & $5.7^{\mathrm{bc}}$ & $4.6^{\mathrm{abc}}$ & $4.3^{\mathrm{ab}}$ & $6.3^{\mathrm{c}}$ & $3.9^{\mathrm{a}}$ & $4.1^{\mathrm{ab}}$ \\
\hline
\end{tabular}

* Values marked with different letters in the same row are significantly different $(P \leq 0.05)$ according to the LSD multiple comparison test. 
Table 5

Mean scores of the significant sensory attributes of sliced potatoes at packaging time (0 day).

\begin{tabular}{llllllll}
\hline Attribute & & Arinda & Elodie & Erika & Fontane & Marabel & Ranomi \\
\hline \multirow{2}{*}{ Rosemary odor } & A & $1.0^{\mathrm{a}}$ & $1.0^{\mathrm{a} *}$ & $1.0^{\mathrm{a}}$ & $1.0^{\mathrm{a}}$ & $1.0^{\mathrm{a}}$ & $1.0^{\mathrm{a}}$ \\
& B & $5.4^{\mathrm{bc}}$ & $4.7^{\mathrm{bc}}$ & $5.4^{\mathrm{bc}}$ & $5.7^{\mathrm{bc}}$ & $4.4^{\mathrm{b}}$ & $6.1^{\mathrm{c}}$ \\
Sweet & A & $3.9^{\mathrm{bc}}$ & $1.9^{\mathrm{a}}$ & $3.2^{\mathrm{ac}}$ & $4.6^{\mathrm{c}}$ & $2.6^{\mathrm{b}}$ & $3.5^{\mathrm{bc}}$ \\
\multirow{4}{*}{ Rosemary flavor } & B & $4.0^{\mathrm{bc}}$ & $2.8^{\mathrm{ab}}$ & $2.9^{\mathrm{ab}}$ & $3.0^{\mathrm{ab}}$ & $2.7^{\mathrm{ab}}$ & $2.8^{\mathrm{ab}}$ \\
& A & $1.0^{\mathrm{a}}$ & $1.0^{\mathrm{a}}$ & $1.0^{\mathrm{a}}$ & $1.0^{\mathrm{a}}$ & $1.0^{\mathrm{a}}$ & $1.0^{\mathrm{a}}$ \\
& B & $5.3^{\mathrm{b}}$ & $5.6^{\mathrm{b}}$ & $6.0^{\mathrm{b}}$ & $5.9^{\mathrm{b}}$ & $5.8^{\mathrm{b}}$ & $6.0^{\mathrm{b}}$ \\
\hline
\end{tabular}

A: dipping in peanut oil; B: dipping in peanut oil and rosemary essential oil.

* Values marked with different letters in the same row are significantly different $(P \leq 0.05)$ according to the LSD multiple comparison test.

Table 6

Mean scores of the significant sensory attributes of sliced potatoes at the end of cold storage time (11 days).

\begin{tabular}{llllllll}
\hline Attribute & & Arinda & Elodie & Erika & Fontane & Marabel & Ranomi \\
\hline Rosemary odor & A & $1.0^{\mathrm{a}}$ & $1.0^{\mathrm{a} *}$ & $1.0^{\mathrm{a}}$ & $1.0^{\mathrm{a}}$ & $1.0^{\mathrm{a}}$ & $1.0^{\mathrm{a}}$ \\
& $\mathrm{B}$ & $3.3^{\mathrm{b}}$ & $5.0^{\mathrm{c}}$ & $3.9^{\mathrm{bc}}$ & $4.9^{\mathrm{c}}$ & $3.4^{\mathrm{b}}$ & $5.0^{\mathrm{c}}$ \\
Off-odor & $\mathrm{A}$ & $2.2^{\mathrm{a}}$ & $1.7^{\mathrm{a}}$ & $4.1^{\mathrm{b}}$ & $1.8^{\mathrm{a}}$ & $1.5^{\mathrm{a}}$ & $1.5^{\mathrm{a}}$ \\
& $\mathrm{B}$ & $1.5^{\mathrm{a}}$ & $1.3^{\mathrm{a}}$ & $1.7^{\mathrm{a}}$ & $1.2^{\mathrm{a}}$ & $1.3^{\mathrm{a}}$ & $2.0^{\mathrm{a}}$ \\
Floury & $\mathrm{A}$ & $6.4^{\mathrm{f}}$ & $6.1^{\mathrm{df}}$ & $5.6^{\mathrm{bf}}$ & $4.5^{\mathrm{ad}}$ & $4.5^{\mathrm{ad}}$ & $3.6^{\mathrm{a}}$ \\
Rosemary flavor & B & $5.7^{\mathrm{cf}}$ & $4.6^{\mathrm{ae}}$ & $4.3^{\mathrm{ac}}$ & $6.3^{\mathrm{ef}}$ & $3.9^{\mathrm{ab}}$ & $4.1^{\mathrm{ac}}$ \\
& A & $1.0^{\mathrm{a}}$ & $1.0^{\mathrm{a}}$ & $1.0^{\mathrm{a}}$ & $1.0^{\mathrm{a}}$ & $1.0^{\mathrm{a}}$ & $1.0^{\mathrm{a}}$ \\
& B & $4.0^{\mathrm{b}}$ & $4.6^{\mathrm{bc}}$ & $4.1^{\mathrm{bc}}$ & $5.3^{\mathrm{c}}$ & $4.9^{\mathrm{bc}}$ & $4.7^{\mathrm{bc}}$ \\
\hline
\end{tabular}

A: dipping in peanut oil; B: dipping in peanut oil and rosemary essential oil.

* Values marked with different letters in the same row are significantly different $(P \leq 0.05)$ according to the LSD multiple comparison test.

cultivars. Arinda and Fontane were also the most adhesive. At the 11th day of storage, samples were significantly different for firmness, offodor, floury and off-flavor. The cv. Erika had the highest intensity of the descriptors off-odor and off-flavor.

For samples B, at packaging time there were no significant sensory differences. After 4 and 11 days of storage, only the attribute floury significantly differentiated samples; while after 7 days, samples were significantly different in terms of firmness and floury. Throughout storage time, cv. Fontane showed the highest intensity for floury.

The results of the comparison of samples $\mathrm{A}$ and $\mathrm{B}$, at packaging time and after 11 days of cold storage, are reported in Tables 5 and 6 , respectively. At packaging time, samples were significantly different for the attributes rosemary odor and flavor, and sweet. Rosemary odor was mostly perceived in cv. Ranomi, while the flavor was similar for all tested varieties. Cv. Fontane A and cv. Arinda B samples had the highest intensity of sweet.

After 11 days of cold storage, samples A and B were significantly different for the attributes rosemary odor and flavor, as observed at the production day, but also for off-odor and floury descriptors. At this time, the highest intensity of off-odors was perceived in Erika potato slices dipped in peanut oil, while cv. Fontane treated as B evidenced the highest intensity of rosemary flavor and floury. The rosemary odor was not differently perceived in Elodie, Ranomi and Fontane.

\section{Conclusion}

Fresh-cut potatoes, already peeled, cut and packed, represent an interesting commercial alternative to pre-cooked or frozen potatoes, considering the consumer preference for minimally processed foods that retain characteristics of freshness.

Results showed that the synergistic use of REO and vacuum packaging, combined with refrigerated storage, can be a viable strategy for the quality preservation of minimally processed potatoes, intended to be cooked with the sous vide technique. In particular, the addition of
REO to the fresh-cut product had a positive effect on texture, and on the growth of mesophilic bacteria and Enterobacteriaceae over the storage period, although with different efficacy among cultivars. The EO addition also ensured a certain retention of ascorbic acid, total polyphenol content, and antioxidant activity. Among cultivars, Marabel reported a significantly higher total polyphenol content and the lowest reduction for the ascorbic acid level during cold storage.

With regard to the sensory analysis, only potato samples without REO showed the negative descriptors off-odors and off-flavors at the end of the considered period, thus highlighting a good attitude of potato slices to be processed with the addition of REO and cooked in sous vide bags.

By comparing potato cultivars, Fontane and Marabel showed good performances in the experimental trial, intended as average qualitative and microbiological characteristics, while Ranomi and Erika were not suitable to be processed by the proposed technological process.

\section{Funding}

This work was financially supported by Project "Utilizzo integrato di approcci tecnologici innovativi per migliorare la shelf-life e preservare le proprietà nutrizionali di prodotti agroalimentari (shelf-life)" (PON 02_00451-3361909).

\section{Acknowledgements}

The authors also thank Dr. Bruno Parisi (CREA-CIN) for having provided the 'seed' tuber material and Mr. Angelo Litrico (Catania University) for his excellent technical assistance in conducting the field trial.

\section{References}

Ayala-Zavala, J. F., Gonzales-Aguilar, G., \& Del-Toro-Sanchez, L. (2009). Enhancing safety and aroma appealing of fresh-cut fruits and vegetables using the antimicrobial and aromatic power of essential oils. Journal of Food Science, 74, 84-91.

Baldwin, D. E. (2012). Sous vide cooking: A review. International Journal of Gastronomy and Food Science, 1, 15-30.

Brand-Williams, W., Cuvelier, M. E., \& Berset, C. (1995). Use of a free radical method to evaluate antioxidant activity. Lebensmittel-Wissenschaft und -Technologie, 22, 25-30.

Buono, V., Paradiso, A., Serio, F., Gonnella, M., De Gara, L., \& Santamaria, P. (2009). Tuber quality and nutritional components of "early" potato subjected to chemical haulm desiccation. Journal of Food Composition and Analysis, 22, 556-562.

Cabezas-Serrano, A. B., Amodio, M. L., Cornacchia, R., Rinaldi, R., \& Colelli, G. (2009). Screening quality and browning susceptibility of five artichoke cultivars for fresh-cut processing. Journal of the Science of Food and Agriculture, 89, 2588-2594.

Cantos, E., Tudela, J. A., Gil, M. I., \& Espín, J. C. (2002). Phenolic compounds and related enzymes are not rate-limiting in browning development of fresh-cut potatoes. Journal of Agricultural and Food Chemistry, 50, 3015-3023.

Chen, Z., Zhu, C., Zhang, Y., Niu, D., \& Du, J. (2010). Effects of aqueous chlorine dioxide treatment on enzymatic browning and shelf-life of fresh-cut asparagus lettuce (Lactuca sativa L.). Postharvest Biology and Technology, 58, 232-238.

CNERNA-CNRS (1996). Produits de la IVe gamme. In J. Jouve (Ed.). La qualité microbiologique des aliments (maîtrise et critères) (pp. 73-98). (2nd ed.). Paris, France: Polytechnica.

Cornacchia, R., Cabezas-Serrano, A. B., Amodio, M. L., \& Colelli, G. (2011). Suitability of 4 potato cultivars (Solanum tuberosum L.) to be processed as fresh-cut product. Early cultivars. American Journal of Potato Research, 88, 403-412.

Dale, M. F. B., Griffiths, D. W., \& Todd, D. T. (2003). Effects of genotype, environment, and postharvest storage on the total ascorbate content of potato (Solanum tuberosum) tubers. Journal of Agricultural and Food Chemistry, 51, 244-248.

Fabbri, A. D. T., \& Crosby, G. A. (2016). A review of the impact of preparation and cooking on the nutritional quality of vegetables and legumes. International Journal of Gastronomy and Food Science, 3, 2-11.

FDA (2013). Food code: Recommendations of the United States public health service food and drug administration. USA: Department of Health and Human Service.

García-Segovia, P., Andrés-Bello, A., \& Martínez-Monzo, J. (2008). Textural properties of potatoes (Solanum tuberosum L., cv. Monalisa) as affected by different cooking processes. Journal of Food Engineering, 88, 28-35.

ISO 8586 (2012). Sensory analysis - General guidelines for the selection, training and monitoring of selected assessors and expert sensory assessors. International Organization for Standardization.

İnceoğlu, O., Salles, J. F., van Overbeek, L., \& van Elsas, J. D. (2010). Effects of plant genotype and growth stage on the betaproteobacterial communities associated with different potato cultivars in two fields. Applied and Environmental Microbiology, 76, 
3675-3684.

Jiang, Y., Wu, N., Fu, Y, J., Wang, W., Luo, M., Zhao, C., et al. (2011). Chemical composition and antimicrobial activity of the essential oil of rosemary. Environmental Toxicology and Pharmacology, 3, 63-68.

Jin, P., Wu, X., Xu, F., Wang, X., Wang, J., \& Zheng, Y. (2012). Enhancing antioxidant capacity and reducing decay of Chinese bayberries by essential oils. Journal of Agricultural and Food Chemistry, 60, 3769-3775.

Licciardello, F., Lombardo, S., Rizzo, V., Pitino, I., Pandino, G., Strano, M. G., et al. (2018). Integrated agronomical and technological approach for the quality maintenance of ready-to-fry potato sticks during refrigerated storage. Postharvest Biology and Technology, 136, 23-30.

Licciardello, F., Pandino, G., Barbagallo, R. N., Lombardo, S., Restuccia, C., Muratore, G., et al. (2017). Quality traits of ready-to-use globe artichoke slices as affected by genotype, harvest time and storage time. Part II: Physiological, microbiological and sensory aspects. LWT-Food Science and Technology, 79, 554-560.

Lombardo, S., Lo Monaco, A., Pandino, G., Parisi, B, \& Mauromicale, G. (2013a). The phenology, yield and tuber composition of 'early' crop potatoes: A comparison between organic and conventional cultivation systems. Renewable Agriculture and Food Systems, 28, 50-58.

Lombardo, S., Pandino, G., \& Mauromicale, G. (2013b). The influence of growing en vironment on the antioxidant and mineral content of "early" crop potato. Journal of Food Composition and Analysis, 32, 28-35.

Lombardo, S., Pandino, G., \& Mauromicale, G. (2014). The mineral profile in organically and conventionally grown "early" crop potato tubers. Scientia Horticulturae, 167, 169-173.

Lombardo, S., Pandino, G., \& Mauromicale, G. (2017). The effect on tuber quality of an organic versus a conventional cultivation system in the early crop potato. Journal of Food Composition and Analysis, 62, 189-196.

Lombardo, S., Restuccia, C., Pandino, G., Licciardello, F., Muratore, G., \& Mauromicale, G. (2015). Influence of an $\mathrm{O}_{3}$-atmosphere storage on microbial growth and antioxidant contents of globe artichoke as affected by genotype and harvest time. Innovative Food Science and Emerging Technologies, 27, 121-128.

Mauromicale, G., Signorelli, P., Ierna, A., \& Foti, S. (2003). Effects of intraspecific competition on yield of early potato grown in Mediterranean environment. American Potato Journal, 80, 281-288.
Moreno, S., Scheyer, T., Romano, C. S., \& Vojnov, A. A. (2006). Antioxidant and antimicrobial activities of rosemary extracts linked to their polyphenol composition. Free Radical Research, 40, 223-231.

Muratore, G., Restuccia, C., Licciardello, F., Lombardo, S., Pandino, G., \& Mauromicale, G. (2015). Effect of packaging film and antibrowning solution on quality main tenance of minimally processed globe artichoke heads. Innovative Food Science \& Emerging Technologies, 31, 97-104.

Nicoli, M. C., Anese, M., \& Parpinel, M. (1999). Influence of processing on the antioxidant properties of fruit and vegetables. Trends in Food Science \& Technology, 10, 94-100.

Ojeda-Sana, A. M., van Baren, C. M., Elechosa, M. A., Juárez, M. A., \& Moreno, S. (2013). New insights into antibacterial and antioxidant activities of rosemary essential oils and their main components. Food Control, 31, 189-195.

Özcan, M. M., \& Chalchat, J. C. (2008). Chemical composition and antifungal activity of rosemary (Rosmarinus officinalis L.) oil from Turkey. International Journal of Food Sciences \& Nutrition, 59, 691-698.

Rizzo, V., \& Muratore, G. (2009). Effects of packaging on shelf life of fresh celery. Journal of Food Engineering, 90, 124-128.

Scuderi, D., Restuccia, C., Chisari, M., Barbagallo, R. N., Caggia, C., \& Giuffrida, F. (2011). Salinity of nutrient solution influences the shelf-life of fresh-cut lettuce grown in floating system. Postharvest Biology and Technology, 59, 132-137.

Singleton, V. L., \& Rossi, J. A. (1965). Colorimetry of total phenolics with phosphomolybdic phosphotungstic acid reagents. American Journal of Enology and Viticulture, 16, 144-158.

Tudela, J. A., Cantos, E., Espiän, J. C., Tomaäs-Barberaän, F. A., \& Gil, M. I. (2002). Induction of antioxidant flavonol biosynthesis in fresh-cut potatoes. Effect of domestic cooking. Journal of Agricultural and Food Chemistry, 50, 5925-5931.

UNI 10957 (2003). Sensory analysis - method for establishing a sensory profile. Foodstuffs And Beverages. Ente Nazionale Italiano di Unificazione, Milano, Italia.

Valero, D., Valverde, J. M., Martinez-Romero, D., Guillen, F., Castillo, S., \& Serrano, M. (2006). The combination of modified atmosphere packaging with eugenol or thymol to maintain quality, safety and functional properties of table grapes. Postharvest Biology and Technology, 41, 317-327.

Wang, C. Y., Wang, S. Y., Yin, J.-J., Parry, J., \& Yu, L. L. (2007). Enhancing antioxidant, antiproliferation, and free radical scavenging activities in strawberries with essential oils. Journal of Agricultural and Food Chemistry, 55, 6527-6532. 